\title{
HEALTH COST OF PESTICIDE USE ON RICE CULTIVATION IN THE SOUTH-WEST REGION OF BANGLADESH
}

\author{
Fariha Farjana $^{* 1}$, Jahangir Polash ${ }^{2}$, Sabiha Ferdousy ${ }^{3}$ \\ 1. *Corresponding Author: Assistant professor, Economics Discipline, Khulna University, Khulna, Bangladesh \\ Email : fariha_farjana@yahoo.com \\ 2. Economics Discipline, Khulna University, Khulna, Bangladesh \\ 3. Economics Discipline, Khulna University, Khulna, Bangladesh
}

\begin{abstract}
The study concentrates on assessing health hazards caused by pesticide spray in rice cultivation in the South-west region of Bangladesh. The data particularized that the probability of facing discomfort due to pesticide exposure is 79 percent. The cost-of-illness (Mitigation cost and income loss due to sickness) and avertive action are considered to estimate pesticide use costs. For health cost estimation, a household survey on rice farmers was conducted. The data were collected through an interview method by using a well-structured questionnaire. Logit, Probit, Poission regression, and Negative binomial regression models have been applied in this study. The predicted probability of falling sick from pesticide-related symptoms is significantly higher among individuals who apply pesticides with high chemical concentrations. For both the logit and probit models, it is statistically significant at a 5 percent significance level. On the other hand, an Integrated Pest Management (IPM) application, first aid knowledge, avertive action, treatment facilities, and knowledge level help reduce the probability of diseases caused by pesticide exposure. Finally, the study finds BDT 5273 per person per season as the health cost for pesticide application-oriented health hazard.
\end{abstract}

KEYWORDS: Pesticide use, Avertive action, Mitigation action, Health Cost.

\section{INTRODUCTION}

Nowadays, in order to secure high yield, Pesticides are frequently used in the agriculture sector. However, rapid use of it causes contamination of soil, ground, and surface water. It also increases the health risk of farmers. Pimentel (2005) mentioned that every year worldwide uses of pesticides causes 26 million non-fatal poisonings, among which three million affected people are hospitalized, 220 thousand died, and about 750 thousand experiences chronic illnesses. Exercise of pesticide application has significant chronic health effects, including cancer, neurological effects, diabetes, respiratory diseases, fatal diseases, and genetic disorders. These health effects are different depending on the degree and the type of exposure (Choudhary et al., 2014).

Recently for developing countries, the present agricultural systems have "locked in" farmers in the culture of pesticide spray, and it "entrapped" them in pesticides that cause health risk (Atreya et al., 2012). Peasants apply pesticide as an essential input to ensure optimal harvest (Kabir \& 
Rainis, 2012). Palikhe (2002) has argued that pesticides are generally used to secure yields and improve food quality, but their non-cautious use pollutes the environment and creates a health hazard.

Major health-related issues due to pesticide exposure are skin irritations, eye irritation, vomiting, shortness of breath, headache, fever, stomach poisoning, skin effect, respiratory tract effect, pain in muscles, joint or bone pain, decrease sight, sputum formation, wheezing, blurred vision, burning of the nose, tenderness, decreased chest expansion a rash or cramps and breathing problem (Choudhary et al., 2014; Miah et al., 2014; Bhattacharjee et al., 2013; Atreya, 2005; Dasgupta et al., 2005a; Pimentel, 2005; Khan, 2004; Maumbe \& Swinton, 2002; Pingali et al., 1994). Hence, Wilson and Tisdell (2001) claim that proper economic valuation of pesticide-centric risk to human health is essential to trace out for effective policy formulation. Therefore, the paper focuses on the health cost estimation of farmers who use pesticides. To address the objective, the following research questions are considered:

i. What is the impact on farmers' health concerning the dose of pesticide use?

To answer this question, the study investigates the farmer's positive or negative response in the probability of falling sick concerning pesticide use. In this context, authors develop a dose-response model followed by Atreya (2007) and Devi (2007).

ii. What is the amount of monetary loss due to the health cost of pesticide toxicity?

This research question answers the health cost of pesticide exposure. Authors consider medical cost and workday loss as a cost that result from pesticide exposure. The cost of taking avertive action is also included as a cost component.

\section{MATERIALS AND METHOD}

\subsection{Study Area and Sampling Technique}

Koyra Upazilla has significant importance in agricultural activities, especially for rice production (Khanom, 2016). Modinabad and Kalna are the two villages considered the study area, and 35 samples were collected from each of the regions (See Table 1). A purposive sampling technique was considered for sample selection. Peasants who spray pesticide were considered the sample for analyzing the impact of pesticide exposure on health costs.

\subsection{Data Collection}

Primary data were used for the study. Data about the farmer's socio-demographic feature, avertive action-centric activities, mitigation activities, details of sick days related information, smoking habits, working hour, and income were collected by interview schedule method. Data on pesticide exposure and health cost (mitigation cost, avertive cost, and workday loss) were collected using a recall method of last season of paddy harvesting. The pattern of pesticide use is different for different crops. Its consequences are also different. Hence, to ensure group homogeneity of the data, one crop was considered. Here, the study considers paddy crop as it is dominantly cultivated in the study area. Details of the variables are mentioned in Table 2. 


\subsection{Analytical Framework}

\section{Analytical Tool for Research Question 1}

The Dose-Response model estimates the health risk associated with pollution. It measures the relationship between the probability of illness and the level of pollution arising from pesticide exposure and other variables that affect the individual's health status (Devi, 2007). In this study, the peasant's probability of falling sick due to pesticide exposure was estimated through dose-response. Since the dependent variable is dichotomous maximum likelihood method is followed for probit model estimation.

On the other hand, avertive action is an essential issue of this study. It concentrated on the farmers' protective activities to protect themselves from discomfort caused by pesticide use. The probability of taking avertive action was considered as a function of the level of pesticide exposure and the vector of explanatory variables. This study follows other scholars' studies (Atreya, 2008; Devi, 2007; Dasgupta et al., 2005b; Dasgupta et al., 2003). The econometric model specification used for dose-response and avertive action function is:

$$
\begin{aligned}
& S_{i}=\sum_{i=1}^{n} \beta_{i} x_{i}+\mu_{i} \\
& Y_{i}=\sum_{i=1}^{n} \alpha_{i} z_{i}+\theta_{i}
\end{aligned}
$$

In equation 1 and $2, \mathrm{E}\left(\mu_{i}\right)=0, \mathrm{E}\left(\theta_{i}\right)=0$, Var $\mathrm{E}=\sigma^{2} \mathrm{i}$ and Var $\mathrm{E}\left(\theta_{i}\right)=\sigma^{2} \mathrm{i} ; S_{i}$ is a binary dependent variable of the probability of falling sick, $\mathrm{Yi}$ is the probability of farmers taking avertive action, $\beta_{i}$ is the vector coefficient of the probability of falling sick, $\alpha_{i}$ is the vector coefficient of the probability of taking avertive action, $x_{i}$ and $z_{i}$ are the vector of explanatory variables. The vector of explanatory variables comprises individual characteristics, pesticide dose, socioeconomic, and some environmental factors (Atreya, 2008). Here, pesticide dose is defined as concentration $(\mathrm{ml}$ or $\mathrm{gm} / \mathrm{l})$ multiplied by spray duration $(\mathrm{h} /$ day) i.e.

$$
D=C_{n i}\left(t_{i}\right)
$$

In equation 3, a dose of pesticide (D) is the magnitude of pesticide exposure. $C_{n}(t)$ is the concentration of exposure as a function of time (t) (Atreya, 2008). The greater the pesticide exposure, the greater is the probability of falling sick and taking avertive action. The data in this regard were collected from a field survey.

\section{Analytical Tool for Research Question 2}

This segment of the paper identifies the monetary cost associated with acute symptoms resulted from pesticide exposure. The cost of illness method is used to determine the monetary loss associated with health effects arise from pesticide application following Devi (2007). Therefore, the illness cost comprises doctor consultation fee, hospitalization cost, laboratory test cost, medicine cost, travel cost to the doctor or hospital from home, dietary expenses resulting from illness, and workdays' loss. 


\section{Health Cost}

To estimate health cost, the authors preferred the Tobit model to identify the factors influencing the mitigation cost arise from pesticide exposure. The equation for the Tobit model is as follows:

$$
C_{i}=\sum_{i=1}^{n} \gamma_{i} k_{i}+\epsilon_{i}
$$

In equation $4, C_{i}$ is the associated health cost of pesticide exposure, $\gamma_{i}$ is the vector of coefficient, and $k_{i}$ is the vector of the explanatory variable.

\section{Income Loss}

The same Tobit model is used to explore the factors that influence the income loss of pesticide spraying. As a result, adverse health effects of pesticide exposure. In equation $5, I$ is the associated income loss of pesticide exposure, $L_{i}$ is the vector coefficient of income loss, and $P_{i}$ is the vector of the explanatory variable.

$$
I_{i}=\sum_{i=1}^{n} L_{i} p_{i}+d_{i}
$$

\section{Sick Days}

This part of the study tries to assess how the average sick days due to chemical pesticides are associated with other factors. The authors considered the Poisson regression (PR) model to estimate sick days $\mathrm{S}_{\mathrm{it}}$. It was the count type of data. Chicago and Trivedi (1998) urged that PR is suitable for the dependent variable of the count data type. Here $i$ is the number of individual respondents, and $t$ is the duration of illness. Therefore, considering pesticide exposure related sickness $\mathrm{S}_{\mathrm{it}}$, the Poisson regression model is:

$$
\begin{aligned}
& \operatorname{Pr}\left(S_{i t}=S / X_{i t}\right)=f\left(S_{i t} / \lambda_{i t}\right)=\frac{\lambda_{i t}^{S i t} \exp (-\lambda i t)}{S_{i t}} ;(S=0,1,2, \ldots \ldots ., 9) \\
& \log \left(\lambda_{i t}\right)=X_{i t} \beta_{i}+\mu_{i} ; \quad \mu_{i} \sim N\left(0, \sigma_{\mu}^{2}\right)
\end{aligned}
$$

In equation 6 and $7, \lambda_{i t}$ depicts the mean value of the number of sick days, $\beta_{i}$ implies the vector of regression coefficients, and $X_{i t}^{\prime}$ is the vector of explanatory variables. The Poisson distribution is developed on a very restrictive assumption, i.e., equality of mean and variance of the dependent variable. If this assumption is violated, then the alternative approach is to go for Negative Binomial Regression (NBR) (Power \& Xie, 1999). Hence, modification of the PR model in NBR as:

$$
\begin{aligned}
& \operatorname{Pr}\left(S_{i t}=S / X_{i t}\right)=f\left(S_{i t} / \alpha, \lambda_{i t}\right)=\frac{r\left(S_{i t}+\alpha\right)}{S_{i t} ! r(\alpha)}\left(\frac{\alpha}{\alpha+\lambda_{i t}}\right) \alpha\left(\frac{\lambda_{i t}}{\alpha+\lambda_{i t}}\right)^{S}{ }_{i t} \\
& \log \left(\lambda_{i t}\right)=X_{i t} \beta_{i}+\mu_{i} ; \quad \mu_{i} \sim N\left(0, \sigma_{\mu}^{2}\right)
\end{aligned}
$$

Here $\alpha$ implies dispersion parameter, which quantifies overdispersion. The mean of the dependent variable in NBR is still depicted by $\mathrm{E}\left(\mathrm{S}_{\mathrm{it}} / \mathrm{X}_{\mathrm{it}}\right)=\lambda_{\mathrm{it}}$. However, the variance is represented as $\mathrm{V}\left(\mathrm{S}_{\mathrm{it}} / \mathrm{X}_{\mathrm{it}}\right)=\lambda_{\mathrm{it}} / \alpha$. Therefore, the study can move to NBR when $\alpha$ approach infinity.

\section{Health Cost Estimation}

Cost of illness (COI) is the most commonly and popularly used method for estimating health cost due to health damage arises from any exposure (Devi, 2007). For this paper, the cost of 
illness comprises the consultation fee, hospitalization cost, laboratory test cost, medicine cost, travel cost to the doctor or hospital from home, dietary expenses resulting from illness, loss of earnings due to loss of working days or loss of productivity. To estimate the monetary loss of pesticide exposure, this study followed the cost of illness approach used by Atreya (2007). The total predicted health cost (THC) of pesticide exposure is as follows:

$$
T H C=S^{*}(A M C+A I L)+Y^{*} A A C \text { for pesticide users }
$$

We can estimate (predicated probability of illness due to pesticide exposure of pesticide users) and $\mathrm{Y}$ (predicated probability of avertive action) from equations 1 and 2. Apart from this, AMC is the average mitigation costs, AIL is the average loss of income due to pesticide exposure, and AAC is the average cost of avertive action. Average Avertive Cost (AAC) reflects the cost of preventive action taken to direct exposure to the pesticide, such as masks, boots, pants, sprayers, etc. Avertive equipment may also have multiple uses. However, this study considered avertive equipment purchased specifically to handle pesticides following Atreya (2007).

\section{RESULTS AND DISCUSSION}

\subsection{Descriptive Analysis}

Table 3 depicts descriptive statistics of the variables used in different models in the study. $79 \%$ of respondents experienced discomfort after pesticide spray. The average level of education is 7.91 years, with a standard deviation of 2.76. The minimum working hour per day is 6 hours, and the maximum value is 8 hours, with average working hours 6.87 and a standard deviation of 0.51 . A mean workday per week is 6.74 , with a standard deviation of 0.47 .

The minimum medical cost for the last season is BDT 0 , and the maximum medical cost is BDT 6175 , with an average medical cost of 2215.96 and a standard deviation of 1850.97 . Average sick days were 3.04 , with a standard deviation of 2.78 in the last season due to pesticide exposure. The maximum value of the sick day is nine, and the minimum value is 0 . Here, 0 sick days implies that sprayers did not experience any health hazard after pesticide spray.

\subsection{Prevalence of Pesticide Related Diseases}

Table 4 depicts the probability of pesticide sprayer peasants' facing several sicknesses due to pesticide exposure. Headache, eye irritation, weakness, and vomiting are the most common phenomenon of pesticide exposure.

\subsection{Probability of Falling Sick}

A dose-response function is used to calculate the probability of falling sick. Table 5 postulates the result of dose-response function estimation. Here, the numerical value 1 indicates respondents suffered from any sorts of discomfort due to pesticide application for the last cultivating season and 0 for those who are not suffering from pesticide-related adverse health effects.

Here, one unit increase in the amount of pesticide concentration increased the probability of feeling discomfort by 1.098 percent in the logit model and 1.384 percent in the probit model. An increase in age by one year reduces the probability of feeling discomfort due to pesticide exposure by 3.673 percent and 5.006 percent, respectively. However, subjects' exposure to pesticide spray for a more extended time horizon induces a higher probability of falling sick by 
0.044 percent in the logit model and 0.060 percent in the probit model. Therefore, a U-shaped association prevails between age and the likelihood of falling sick. Young people are less vulnerable to pesticide exposure, but age square claims that older adults are at higher risk of facing discomfort. The use of IPM in green pesticides rather than chemical pesticides helps farmers reduce pesticide-related diseases by 14.39 percent and 16.56 percent, respectively. Besides, availabilities of treatment facilities help to reduce the adverse health effect of pesticide exposure. Moreover, the increase in workdays per week and pesticide preparation time boosts the probability of facing discomfort due to pesticide application in the logit and probit model.

\subsection{Avertive Action for Different Body Parts}

Data in Table 6 shows the pesticide sprayers' probability of taking avertive action. The data reveals that maximum pesticide sprayers have a higher probability of taking avartive action for body cover $(0.61)$, face care (0.7) and leg care ( 0.7$)$ for different body parts. Hence, the pesticide sprayers' total probability of taking avertive action was 0.7

\subsection{Avertive Behavior and Cost Specification}

Table 7 shows sector-wise avertive behavior and cost specification of the pesticide sprayers. Among 70 respondents, only 49 respondents adopt avertive action. Here, for foot protection corresponding protective option were boots and shoes. The average cost for foot care and head cover are BDT 518.46 and BDT 137.71 , respectively. For eye care, only 24 respondents use sunglasses, and the average cost is BDT 140.21. On the other hand, among 49 farmers, 39 farmers use gloves, and the average cost for gloves is BDT114.74 per person. The 49 respondents used the mask for the face's safety, and the corresponding average cost for masks is BDT 73.93. Furthermore, 31 respondents use full-length trousers for leg protection, and their average protection cost is BDT 510.81 .

\subsection{Probability of Taking Avertive Action}

Table 8 revealed that both in the logit and probit model, pesticide sprayers, who took avertive action experience a lower probability of facing discomfort due to pesticide exposure compared to those who did not adopt avertive action. The value is 1 for those who take protective action when spraying chemical pesticide and 0 who do not use protective equipment.

\subsection{Estimation of Loss of Income}

In this part, the authors explore a Tobit model to identify factors that influence income loss due to pesticide application. Table 9 depicts that holding other explanatory variables constant increase of age by one year reduces average income loss by BDT517.281 per season. Keeping the other variable remaining same if the square value of age increases by 1 unit, expected income loss due to pesticide exposure increases by BDT7.28 per season. At an earlier age, farmers had better health status and the ability to avoid adverse health effects of pesticide exposure, but farmers suffered an adverse health effect after an individual age.

Considering other explanatory variables, constant respondents with first aid knowledge can reduce income loss per season by BDT 2899.63 compared to those who do not have first aid knowledge. Keeping other variable constant, an increase in pesticide preparing time by 1 minute raise the average income loss per season by BDT 308.88, and this result is significant at 10 percent significance level. Holding other variables remaining the same increase per week workday by one day increases average income loss per season by BDT 1445.48. 


\subsection{Estimation of Mitigation Cost}

Table 10 depicts parameter estimation of mitigation expenditure. Holding other variables constant increase in age by one year reduces the expected mitigation expenditure per season by BDT 512.70, and the result is significant at a 5 percent significance level.

Holding other variable constant farmers with first aid knowledge expected to decrease mitigation cost per season by BDT 2613.478. An increase in weekly working day by one day increases mitigation expenditure due to pesticide-related diseases by BDT 1498.953, keeping other variables constant, and this result is statistically significant at a 1 percent significance level.

\subsection{Sick Days Estimation Due to Pesticide Exposure}

Poisson regression and negative binomial regression analysis were conducted to explore significant factors that influence respondents' sick days due to pesticide exposure. Here, the dependent variable is the number of sick days. One of the restrictive assumptions of the Poisson regression model is the equality of mean and variance. However, the mean and variance of sick days are not the same for the study. In this context, the authors conducted an over dispersion test, considering the value of alpha $(\alpha)$ in table 11 .

Null Hypothesis, $\mathrm{H} 0=\alpha=0$

There was no overdispersion in the data.

Alternative Hypothesis, $\mathrm{H} 1=\alpha \neq 0$

There was over dispersion in the data.

Here, the corresponding test statistics for $Z$ value was 2.10 where $Z=\alpha / S E(\alpha)$

So, the negative binomial model is justified in this analysis.

Pesticide concentration significantly increases expected sick days due to pesticide exposure (Table 11). Holding other variables constant, IPM users face lower sick days due to pesticide exposure by 0.5145 times in the poission model and 0.5144787 times in the negative binomial model compared to the non-IPM user, and the result is significant at 1 percent significance level. Taking avertive action reduces pesticide application-related sick days due to chemical exposure by 0.40076 times and 0.4006795 times, respectively, which is significant at a 1 percent significance level, holding other explanatory variables constant. Keeping other variables remaining the same increase in pesticide concentration levels raised expected sick days by 1.0556 and 1.055633 times in the poission and negative binomial regression model. Both of the results are significant at a 1 percent significance level.

\section{CONCLUSION}

The study reveals considerable health costs experienced by the pesticide sprayer. Following the health cost estimation method by Atreya (2008), this study identifies average mitigation cost, income loss due to workdays loss, and avertive cost as BDT2906.31, BDT 2272.77, and BDT 1717.96, respectively (Table 12). Hence, the total cost of pesticide use is BDT 5273.33. The result also manifested that increase in the concentration of pesticides increases the probability of falling sick. Therefore, the sprayer should be careful regarding the mixture of pesticides and their application.

Meanwhile, IPM techniques are found as a beneficial way out to curve pest oriented problem. The data postulated that adoption of IPM techniques reduces the potentiality of pesticide 
sprayers' health hazard by 51 percent. However, the literature suggests the application of IPM needs training, which makes farmers reluctant to apply it. Only 27 percent of the respondent in the study area used the IPM technique. The result was consistent with Atreya et al. (2012), where he stated that "IPM training leads to higher investment for farmers." Therefore, the government should increase training facilities for the peasants at a cheaper rate so that they will be encouraged to adopt IPM techniques of pest control.

Meanwhile, this paper is an exercise to explore the health risk related to pesticide spraying for one cultivation season. Other researchers can explore a wide range of massive national-level studies on annual health costs due to pesticide exposure in total agricultural production due to pesticide use. This future research option can provide a composite scenario about health hazards from pesticide exposure and its associated health cost.

Table 1: Sampling Design

\section{List of Tables and Figures}

\begin{tabular}{|c|c|}
\hline Name of the Village & Number of Samples \\
\hline Modinabad & 35 \\
\hline Kalna & 35 \\
\hline
\end{tabular}

Source: Authors' Compilation

Table 2: List of Variables

\begin{tabular}{|l|l|l|}
\hline Variables & Description & Literature \\
\hline Probability of Falling Sick & $\begin{array}{l}\text { Dichotomous } \\
0=\text { Not Sick } \\
1=\text { Sick }\end{array}$ & Devi (2007) and Atreya (2007) \\
\hline $\begin{array}{l}\text { Probability of Taking } \\
\text { Avertive Action }\end{array}$ & $\begin{array}{l}\text { Dichotomous } \\
0=\text { Not Sick } \\
1=\text { Sick }\end{array}$ & Atreya (2007) \\
\hline $\begin{array}{l}\text { Money Spend to Cure } \\
\text { Diseases }\end{array}$ & BDT Per Person Per Season & Authors' Compilation \\
\hline Loss of Income & BDT Per Person Per Season & Authors' Compilation \\
\hline Sick Days & Day Per Person Per Season & Authors' Compilation \\
\hline Dose of Pesticide & $\begin{array}{l}\text { Pesticide (ml or gm/l)* } \\
\text { (h/day) }\end{array}$ & Devi (2007) \\
\hline Mixing of Pesticide & $\begin{array}{l}\text { Dummy } \\
1=\text { Mixed } \\
0=\text { Otherwise }\end{array}$ & Devi (2007) \\
\hline Age & Years & Devi (2007) and Atreya (2007) \\
\hline Age2 of Individual & Years & Authors' Compilation \\
\hline Education & Years of Schooling & Devi (2007) and Atreya (2007) \\
\hline
\end{tabular}




\begin{tabular}{|l|l|l|}
\hline Variables & Description & Literature \\
\hline $\begin{array}{l}\text { Integrated Pest } \\
\text { Management }\end{array}$ & $\begin{array}{l}\text { Dummy } \\
1=\text { Applicator of } \\
\text { IPM 0= Otherwise }\end{array}$ & Devi (2007) \\
\hline Body Mass Index & Weight/Height2 & Devi (2007) \\
\hline Cultivable Land Area & Bigha & Authors' Compilation \\
\hline $\begin{array}{l}\text { Full Time or Part Time } \\
\text { Sprayer }\end{array}$ & $\begin{array}{l}\text { Dummy } \\
1=\text { Full Time } \\
0=\text { Part-Time }\end{array}$ & Authors' Compilation \\
\hline $\begin{array}{l}\text { Availability of Treatment } \\
\text { Facilities }\end{array}$ & $\begin{array}{l}\text { Dummy } \\
1=\text { Yes } \\
0=\text { Otherwise }\end{array}$ & Authors' Compilation \\
\hline Work Day Per Week & Day & Authors' Compilation \\
\hline Pesticide Preparing Time & Minute & Authors' Compilation \\
\hline Smoking Habit & $\begin{array}{l}\text { Dummy } \\
1=\text { Smoker } \\
0=\text { Non-Smoker }\end{array}$ & Devi (2007) and Atreya (2007) \\
\hline First Aid Knowledge & $\begin{array}{l}\text { Dummy } \\
1=\text { Yes } \\
0=\text { Otherwise }\end{array}$ & Maumbe and Swinton (2002) \\
\hline
\end{tabular}

Source: Authors' Compilation.

Table 3: Descriptive Statistics

\begin{tabular}{|l|r|r|r|r|}
\hline Variable & Mean & Std. Dev. & Min & Max \\
\hline Discomfort & 0.79 & 0.41 & 0 & 1 \\
\hline Mixing of Pesticide & 0.6 & 0.49 & 0 & 1 \\
\hline Age & 40.1 & 7.91 & 26 & 56 \\
\hline Age2 & 1671.37 & 658.91 & 676 & 3205 \\
\hline Education & 7.91 & 2.76 & 3 & 14 \\
\hline IPM Use & 0.27 & 0.45 & 0 & 1 \\
\hline BMI & 24.34 & 1.56 & 20.78 & 30.27 \\
\hline Smoking Habit & 0.33 & 0.47 & 0 & 1 \\
\hline Cultivable Land & 18.34 & 7.85 & 0 & 30 \\
\hline Pesticide Sprayer & 0.99 & 0.12 & 0 & 1 \\
\hline Treatment Facilities & 0.51 & 0.50 & 0 & 1 \\
\hline Avertive Action & 0.49 & 0.50 & 0 & 1 \\
\hline Work Hours per Day & 6.87 & 0.51 & 6 & 8 \\
\hline Work Days Per Week & 6.74 & 0.47 & 5 & 7 \\
\hline
\end{tabular}




\begin{tabular}{|l|r|r|r|r|}
\hline Variable & Mean & Std. Dev. & Min & Max \\
\hline Preparing Time of Pesticide & 6.07 & 1.16 & 3 & 8 \\
\hline Medical Cost & 2215.96 & 1850.97 & 0 & 6175 \\
\hline Sick Days & 3.04 & 2.78 & 0 & 9 \\
\hline Income & 18539.29 & 5182.04 & 7000 & 27000 \\
\hline Expenditure & 17328.57 & 4899.63 & 4500 & 25000 \\
\hline Savings & 5818.57 & 10977.09 & 0 & 50000 \\
\hline Avertive Cost & 1717.96 & 838.68 & 0 & 2120 \\
\hline Income Loss & 2272.77 & 1637.67 & 0 & 6667 \\
\hline
\end{tabular}

Source: Authors' Compilation.

Table 4: Probability of Attack by Pesticide Related Diseases

\begin{tabular}{|lcc|}
\hline Variable Name & Explanation & Value \\
\hline Eye Irritation & $48 / 70$ & 0.686 \\
\hline Headache & $51 / 70$ & 0.729 \\
\hline Breath Problem & $35 / 70$ & 0.5 \\
\hline Vomiting & $46 / 70$ & 0.657 \\
\hline Skin Irritation & $38 / 70$ & 0.542 \\
\hline Fever & $47 / 70$ & 0.671 \\
\hline Pain & $45 / 70$ & 0.643 \\
\hline Decrease Sight & $11 / 70$ & 0.157 \\
\hline Cough & $46 / 70$ & 0.657 \\
\hline Weakness & $51 / 70$ & 0.729 \\
\hline Here $48,51,35,46,38,47,45,11,46$, and 51 are frequency of pesticide-related sickness \\
\hline $55=$ Total Frequency of farmer face discomfort due to pesticide-related sickness \\
\hline $15=$ Total Frequency of farmer do not face discomfort due to pesticide-related sickness \\
\hline $70=$ Total number of observation surveyed \\
\hline $\begin{array}{l}55 / 70=0.786 \text { is the total probability of facing discomfort due to pesticide exposure in the } \\
\text { study area }\end{array}$ \\
\hline
\end{tabular}

Source: Authors' Compilation.

Table 5: Result of Dose-Response Function Analysis

\begin{tabular}{|l|c|c|c|c|}
\hline \multicolumn{4}{|c|}{ Dependent Variable: Probability of Facing Discomfort } \\
\hline & \multicolumn{2}{|c|}{ Logit Model } & \multicolumn{2}{c|}{ Probit Model } \\
\hline Explanatory Variable & Coef. & Marginal Effect & Coef. & Marginal Effect \\
\hline Concentration & $0.31^{* *}$ & 0.0109835 & $0.16^{* *}$ & 0.0138457 \\
\hline Mixing & 0.92 & 0.0368209 & 0.51 & 0.0497237 \\
\hline
\end{tabular}




\begin{tabular}{|l|c|c|c|c|}
\hline \multicolumn{5}{|c|}{ Dependent Variable: Probability of Facing Discomfort } \\
\hline & \multicolumn{2}{|c|}{ Logit Model } & \multicolumn{2}{c|}{ Probit Model } \\
\hline Explanatory Variable & Coef. & Marginal Effect & Coef. & Marginal Effect \\
\hline Age & $-1.0^{*}$ & -0.0367349 & $-0.57^{*}$ & -.0500654 \\
\hline Age2 & $0.01^{*}$ & 0.0004443 & $0.01^{*}$ & 0.0006002 \\
\hline Education & 0.07 & 0.0025146 & 0.03 & 0.0030133 \\
\hline IPM & -2.23 & -0.1439332 & $-1.16^{*}$ & -0.1655547 \\
\hline BMI & $0.65^{*}$ & 0.0224949 & $0.33^{*}$ & 0.0286576 \\
\hline Cultivable Land & -0.06 & -.0034253 & -0.06 & -0.0050214 \\
\hline Pesticide Sprayer & 0.18 & 0.0067966 & 0.11 & 0.0104678 \\
\hline Treatment Facilities & $-1.78^{*}$ & -0.068683 & $-0.95^{*}$ & -0.087621 \\
\hline Work Days Per Week & $1.80^{*}$ & 0.0647701 & $0.99^{*}$ & 0.08633 \\
\hline Preparing Time of Pesticide & $1.29^{* *}$ & 0.0464236 & $0.68^{* * *}$ & 0.0592791 \\
\hline Constant & -21.26 & & -9.24 & \\
\hline
\end{tabular}

Source: Authors' Compilation; N.B.: ${ }^{* *} \mathrm{p}<0.01,{ }^{*} \mathrm{p}<0.05,{ }^{*} \mathrm{p}<0.1$

Table 6: Probability of Taking Avertive Action

\begin{tabular}{|lll|}
\hline Variable Name & Explanation & Value \\
\hline Feet care & $39 / 70$ & 0.557 \\
\hline Headcover & $35 / 70$ & 0.5 \\
\hline Eyecare & $24 / 70$ & 0.343 \\
\hline Body cover & $43 / 70$ & 0.614 \\
\hline Hand care & $39 / 70$ & 0.557 \\
\hline Face care & $49 / 70$ & 0.7 \\
\hline Leg care & $49 / 70$ & 0.7 \\
\hline Here $39,35,24,43,39,49$, and 49 are frequency of taking avertive action \\
\hline 49= Total Frequency of farmer take avertive action \\
\hline 21= Total Frequency of farmer does not take avertive action \\
\hline $70=$ Total number of observation surveyed \\
\hline 49/70=0.7 is the total probability of taking avertive action \\
\hline Average Avertive Cost = BDT 1717.96 \\
\hline
\end{tabular}

Source: Authors' Compilation

Table 7: Sector Wise Avertive Cost

\begin{tabular}{|ll|c|c|}
\hline \multicolumn{2}{|c|}{ Type of Avertive behavior } & No. of Respondent Use & Average Cost (BDT) \\
\hline Feet care & Boots & 39 & 518.46 \\
& Shoes & 0 & \\
& Others & 0 & \\
\hline
\end{tabular}




\begin{tabular}{|ll|c|c|}
\hline Type of Avertive behavior & No. of Respondent Use & Average Cost (BDT) \\
\hline Headcover & Hat & 35 & 137.71 \\
& Helmet & 0 & \\
& Others & 0 & 140.21 \\
\hline Eyecare & Glasses & 24 & 543.38 \\
& Others & 0 & 392.22 \\
\hline Body cover & Full sleeved shirt & 34 & 114.74 \\
& Half sleeved shirt & 9 & \\
& Others & 0 & 73.93 \\
\hline Hand care & Gloves & 39 & \\
& Others & 0 & 510.81 \\
\hline Face care & Mask & 49 & 556.94 \\
& Others & 0 & \\
\hline Leg care & Full-length trousers & 31 & \\
& Hard jeans & 18 & \\
& Others & 0 & \\
\hline
\end{tabular}

Source: Authors' Compilation.

Table 8: Result of Avertive Action Analysis in Logit and Probit Model

\begin{tabular}{|l|r|r|r|r|}
\hline \multicolumn{4}{|c|}{ Dependent Variable: Probability of Taking Avertive Action } \\
\hline & \multicolumn{2}{|c|}{ Logit Model } & \multicolumn{2}{|c|}{ Probit Model } \\
\hline Explanatory Variable & Coef. & Marginal Effect & Coef. & Marginal Effect \\
\hline Concentration & $-0.64^{* * *}$ & -0.1578811 & $-0.36^{* * *}$ & -0.143911 \\
\hline Mixing & $3.46^{*}$ & 0.6712321 & $2.07^{*}$ & 0.6775878 \\
\hline Age & 0.39 & 0.0954008 & 0.262 & 0.1027862 \\
\hline Age2 & -0.01 & -0.0012117 & -0.01 & -0.0013186 \\
\hline Education & $-0.51^{*}$ & -0.1272048 & $-0.29^{*}$ & -0.1134545 \\
\hline IPM & $3.37^{*}$ & 0.6600703 & $1.93^{*}$ & 0.6358564 \\
\hline BMI & 0.33 & 0.0820678 & 0.20 & 0.0793387 \\
\hline Cultivable Land & 0.047 & 0.0103053 & 0.03 & 0.0107543 \\
\hline Pesticide Sprayer & $5.15^{* * *}$ & 0.5656332 & $2.91^{* * *}$ & 0.5764699 \\
\hline Treatment Facilities & $4.10^{* * *}$ & 0.766162 & $2.35^{* * *}$ & 0.7566728 \\
\hline Work Days Per Week & -0.15 & -0.0368014 & -0.13 & -0.0529039 \\
\hline Preparing Time of Pesticide & -0.39 & -0.0958673 & -0.29 & -0.1145703 \\
\hline Constant & 0.81 & & -9.24 & \\
\hline
\end{tabular}

Source: Authors' Compilation. N.B.: *** $\mathrm{p}<0.01, * * \mathrm{p}<0.05, * \mathrm{p}<0.1$ 
Table 9: Tobit Model for Income Loss

\begin{tabular}{|lr|r|r|r|}
\hline \multicolumn{5}{|c|}{ Dependent Variable: Income Loss Per Season } \\
\hline Explanatory Variable & Coef. & Std. Err. & $\mathrm{t}$ & $\mathrm{P}>\mathrm{t}$ \\
\hline Age & $-517.281^{* *}$ & 239.94 & -2.16 & 0.03 \\
\hline Age2 & $7.276^{* * *}$ & 2.89 & 2.51 & 0.01 \\
\hline Education & 158.425 & 100.46 & 1.58 & 0.12 \\
\hline IPM & 438.721 & 516.09 & 0.85 & 0.39 \\
\hline BMI & 56.877 & 132.92 & 0.43 & 0.67 \\
\hline Smoking Habit & -246.259 & 400.87 & -0.61 & 0.54 \\
\hline Avertive Action & 379.663 & 1462.89 & 0.26 & 0.79 \\
\hline Sick Days Per Season & 38.749 & 146.59 & 0.26 & 0.79 \\
\hline Concentration of Pesticide & -0.362 & 54.83 & -0.01 & 0.99 \\
\hline First Aid Knowledge & $-2899.63^{* *}$ & 1280.42 & -2.26 & 0.02 \\
\hline Pesticide Preparing Time & $308.881^{*}$ & 189.20 & 1.63 & 0.10 \\
\hline Work Days Per Week & $1445.479 * * *$ & 424.19 & 3.41 & 0.01 \\
\hline Constant & -2492.27 & 6944.81 & -0.36 & 0.721 \\
\hline Sigma & 1435.895 & 148.53 & & \\
\hline LR chi2 & 44.79 & & & \\
\hline Prob > chi2 & 0.00 & & \\
\hline Pseudo R2 & 0.046 & \\
\hline Log-likelihood & -466.54 & & \\
\hline Number of Observation & 70 & \\
\hline
\end{tabular}

Source: Authors' Compilation; N.B.: ${ }^{* * *} \mathrm{p}<0.01,{ }^{* *} \mathrm{p}<0.05,{ }^{*} \mathrm{p}<0.1$

Table 10: Tobit Model for Mitigation Cost

\begin{tabular}{|l|r|r|r|r|}
\hline \multicolumn{5}{|c|}{ Dependent Variable: Mitigation Cost } \\
\hline Explanatory Variable & Coef. & Std. Err. & $\mathrm{t}$ & $\mathrm{P}>\mathrm{t}$ \\
\hline Age & $-512.700^{* *}$ & 254.19 & -2.02 & 0.04 \\
\hline Age2 & $7.094 *$ & 3.06 & 2.32 & 0.02 \\
\hline IPM & 718.452 & 506.11 & 1.42 & 0.16 \\
\hline BMI & 56.691 & 141.38 & 0.40 & 0.69 \\
\hline Smoking Habit & -195.230 & 428.63 & -0.46 & 0.65 \\
\hline Avertive Action & -488.422 & 1354.93 & -0.36 & 0.72 \\
\hline Concentration of Pesticide & -78.181 & 53.46 & -1.46 & 0.14 \\
\hline First Aid Knowledge & $-2613.478^{* *}$ & 1308.61 & -2.00 & 0.05 \\
\hline Work Day Per Week & $1498.953^{* * *}$ & 445.84 & 3.36 & 0.01 \\
\hline
\end{tabular}




\begin{tabular}{|l|r|r|r|r|}
\hline \multicolumn{5}{|c|}{ Dependent Variable: Mitigation Cost } \\
\hline Explanatory Variable & Coef. & Std. Err. & $\mathrm{t}$ & $\mathrm{P}>\mathrm{t}$ \\
\hline Preparing Time of Pesticide & 200.541 & 197.23 & 1.02 & 0.31 \\
\hline Constant & 1631.72 & 7071.47 & 0.23 & 0.818 \\
\hline Sigma & 1570.01 & 162.31 & & \\
\hline LR chi2 & 43.12 & & & \\
\hline Prob > chi2 & 0.00 & & & \\
\hline Pseudo R2 & 0.04 & & & \\
\hline Log-likelihood & -481.39 & & & \\
\hline Number of Observation & 70 & & & \\
\hline
\end{tabular}

Source: Authors' Compilation; N.B.: *** $\mathrm{p}<0.01,{ }^{* *} \mathrm{p}<0.05,{ }^{*} \mathrm{p}<0.1$

Table 11: Estimation of Sick Day in Poisson and Negative Binomial Regression Method

\begin{tabular}{|l|r|r|r|r|}
\hline \multicolumn{5}{|c|}{ Dependent Variable: Frequency of Sick Days } \\
\hline Explanatory Variable & \multicolumn{2}{|c|}{ Poission Regression } & \multicolumn{2}{|c|}{ Negative Binomial Regression } \\
\hline & Coef. & IRR & Coef. & IRR \\
\hline Age & -0.029 & 0.9712 & -0.0293 & 0.9711722 \\
& $(0.101)$ & & $(0.1007)$ & \\
\hline Age2 & 0.0003 & 1.0004 & 0.0004 & 1.000393 \\
& $(0.001)$ & & $(0.0013)$ & \\
\hline Education & -0.027 & 0.9733 & -0.0270 & 0.9733149 \\
& $(0.039)$ & & $(0.0395)$ & \\
\hline IPM & $-0.665^{*} * *$ & 0.5145 & $-0.6646 *$ & 0.5144787 \\
& $(0.277)$ & & $(0.2771)$ & \\
\hline BMI & -0.0115 & 0.9885 & -0.0115 & 0.9885193 \\
& $(0.049)$ & & $(0.0494)$ & \\
\hline Smoking Habit & 0.103 & 1.1089 & 0.1033 & 1.108852 \\
& $(0.140)$ & & $(0.1399)$ & \\
\hline Cultivable Land & 0.0034 & 1.0034 & 0.0034 & 1.003407 \\
& $(0.009)$ & & $(0.0086)$ & \\
\hline Work Hours Per Day & -0.050 & 0.9511 & -0.0502 & 0.9510857 \\
& $(0.249)$ & & $(0.2492)$ & \\
\hline Avertive Action & $-0.915^{* * *}$ & 0.40076 & $-0.9146 * * *$ & 0.4006795 \\
& $(0.341)$ & & $(0.3409)$ & \\
\hline Concentration & $0.054^{* * *}$ & 1.0556 & $0.0541^{* * *}$ & 1.055633 \\
& $0(.020)$ & & $(0.0201)$ & \\
\hline Preparing Time & 0.027 & 1.0277 & 0.0273 & 1.0277 \\
& $(0.0670)$ & & $(0.06691)$ & \\
\hline
\end{tabular}




\begin{tabular}{|l|r|r|r|r|}
\hline \multicolumn{5}{|c|}{ Dependent Variable: Frequency of Sick Days } \\
\hline Explanatory Variable & Poission Regression & Negative Binomial Regression \\
\hline & Coef. & IRR & Coef. & IRR \\
\hline First Aid Knowledge & 0.221 & 1.2470 & 0.2207 & 1.246997 \\
& $(0.219)$ & & $(0.2190)$ & \\
\hline Constant & 1.533 & 4.6305 & 1.532658 & 4.630468 \\
& & & $(2.889321)$ & \\
\hline Lnalpha & -16.41 & -16.45 & -17.27583 & -17.27583 \\
& $(0.47)$ & & $(.2175171)$ & \\
\hline Alpha & 0.0000000749 & 0.0000000749 & 0.0000000314 & 0.0000000314 \\
& $(0.0000000356)$ & & $(0.00000000683)$ & \\
\hline LR chi2 & & & & - \\
\hline Prob > chi2 & & 0.00 & & 138.67 \\
\hline Wald chi2 & & 134.52 & & -117.26012 \\
\hline Log pseudo-likelihood & & -117.53044 & & \\
\hline
\end{tabular}

Source: Authors' Compilation;

N.B.: Robust standard errors in parentheses, ${ }^{* * *} \mathrm{p}<0.01,{ }^{*} \mathrm{p}<0.05,{ }^{*} \mathrm{p}<0.1$

Table 12: Estimation of Health Cost

\begin{tabular}{|l|r|}
\hline Probability of a user being sick (S) & 0.786 \\
\hline Probability of taking avertive action (Y) & 0.7 \\
\hline Average mitigation cost (AMC) & BDT 2906.31 \\
\hline Average Income Loss (AIC) & BDT 2272.77 \\
\hline Average Avertive Cost (AAC) & BDT 1717.96 \\
\hline Average health cost due to pesticide exposure & \\
\hline THC $=\mathrm{S}^{*}$ (AMC+AIC) + Y* AAC & BDT 5273.33 \\
\hline
\end{tabular}

Source: Authors' Compilation

\section{REFERENCES}

Atreya, K. (2005). Health Costs of Pesticide Use in a Vegetable Growing Area, Central mid-hills, Nepal. Himalayan Journal of Sciences, 3(5), 81-84.

Atreya, K. (2008). Health costs from short-term exposure to pesticides in Nepal. Social Science and Medicine, 67(4), 511-519.

Atreya, K. (2007). Pesticide Use in Nepal: Understanding Health Costs from Short-Term Exposure. SANDEE.

Atreya, K., Johnsen, F. H., \& Sitaula, B. K. (2012). Health and Environmental Costs of Pesticide Use in Vegetable Farming in Nepal. Environment, Development, and Sustainability, 14(4), 477-493. 
Bhattacharjee, S., Chowdhury, M.A.Z., Fakhruddin, A.N.M., \& Alam, M.K. (2013). Impact of Pesticide Exposure on Paddy Farmers' Health. Jahangirnagar University Environmental Bulletin, 2, 18-25.

Chicago, A.C., \& Trivedi, P. (1998). Regression Analysis of Count Data. Cambridge: Cambridge University Press.

Choudhary, A., Ali, A.S., \& Ali, S.A. (2014). Adverse Health Effects of Organophosphate Pesticides among Occupationally Exposed Farm Sprayers: A Case Study of Bhopal Madhya Pradesh, India. Asian Journal of Biomedical and Pharmaceutical Sciences, 4(35), 29-34.

Dasgupta, S., Meisner, C., \& Huq, M. (2005a). Health Effects and Pesticide Perception as Determinants of Pesticide Use: Evidence from Bangladesh. Retrieved from http://econ.worldbank.org

Dasgupta, S., Meisner, C., \& Mamingi, N. (2003). Pesticide Traders' Perception of Health Risks: Evidence from Bangladesh. Retrieved from http://econ.worldbank.org

Dasgupta, S., Misner, C., Wheeler, D., Lam, N.T., \& Xuyen, K. (2005b). Pesticide Poisoning of Farm Workers: Implications of Blood Test Results from Vietnam. Retrieved from http://econ.worldbank.org

Devi, P. I. (2007). Pesticide Use in the Rice Bowl of Kerala: Health Costs and Policy Options. Retrieved from http://www.sandeeonline.org/uploads/documents/publication/_PUB_Working_Paper_20_Indira_Devi. pdf.

Kabir, M.H., \& Rainis, R. (2012). Farmers' Perception of the Adverse Effects of Pesticides on Environment: The Case of Bangladesh. International Journal of Sustainable Agriculture, 4(2), 25-32.

Khan, M. (2004). Economic Evaluation of Health Cost of Pesticide Use: Willingness to Pay Method. International Journal of Sustainable Agriculture, 6(1), 40-52.

Khanom, T. (2016). Effect of Salinity on Food Security in the Context of Interior Coast of Bangladesh. Ocean \& Coastal Management, 130, 205-212.

Maumbe, B.M., \& Swinton, S.M. (2002). Hidden Health Costs of Pesticide Use in Zimbabwe's Smallholder Cotton. Long Beach, Central America: American Agricultural Economics Association.

Miah, S.J., Haque, A., Paul, A., \& Rahman, A. (2014). Unsafe Use of Pesticide and Its Impact on Health of Farmers: A Case Study in Burichong Upazila, Bangladesh. Journal of Environmental Science, Toxicology and Food Technology, 8(1), 57-67.

Palikhe, B.R. (2002). Challenges and Options of Pesticide Use: In the context of Nepal. Himalayan Journal of Sciences, 38, 130-141.

Pimentel, D. (2005). Environmental and Economic Costs of the Application of Pesticides Primarily in the United States. Environment, Development, and Sustainability, 7, 229-252.

Pingali, P.L., Marquez, C.B., \& Palis, F.G. (1994). Pesticides and Philippine Rice Farmer Health: A Medical and Economic Analysis. American Journal of Agricultural Economics, 76(3), 587-592.

Power, D.A., \& Xie, Y. (1999). Statistical Method for Categorical Data Analysis. San Deigo: California Academic Press Inc.

Wilson, C., \& Tisdell, C. (2001). Why Farmers Continue to Use Pesticides Despite Environmental, Health, and Sustainability Costs. Ecological Economics, 39, 449-462. 